intervals thereafter, where increase represents normal response. Age- and sex-adjusted regression models were used to examine trends in mean number of components across quartiles of area under the curve (AUC) salivary cortisol. Patterns of mean cortisol response were assessed by MetSyn status using repeatedmeasures analysis of covariance.

Results The study included 373 officers $(74.0 \%$ men) with a mean age of 41.0 years. Prevalence of MetSyn was $25.7 \%$. The mean count of MetSyn components decreased (1.89, 1.75, 1.55, $1.37 ; P<0.01)$ across increasing quartiles of AUC salivary cortisol. The pattern of mean salivary cortisol decreased from baseline $(5.55,4.58,4.47,4.79,4.75 \mathrm{nmol} / \mathrm{L})$ in officers with MetSyn and increased $(5.08,5.82,5.92,5.82,5.60 \mathrm{nmol} / \mathrm{L})$ in their counterparts. The test for interaction between MetSyn status and sample timing was statistically significant $(P<0.001)$.

Conclusions A reduced cortisol response to a high-protein challenge may be associated with MetSyn. Future longitudinal studies could provide useful evidence for planning intervention studies on cardiovascular risk among police officers.

\section{AN EPIDEMIOLOGY OF TRAFFIC ACCIDENT IN NORTHERN THAILAND}

Tawatchai Apidechkul. Mae Fah Luang University, Chiang Rai, Thailand

\subsection{6/oemed-2014-102362.182}

Objectives A cross-section study design aimed to explain the characteristics of traffic accident cases in northern of Thailand.

Method A cross-section study design aimed to explain the characteristics of traffic accident cases in northern of Thailand. The subjects were recruited from 8 hospitals and 7 police stations in the highest case accident areas from hospitals and police stations during 2009- 2012. All medical records and police statements were used as the sources of data collection. All research procedures were approved by the committee for the protection of human subjects of Mae Fah Luang University.

Results Totally 35925 cases had been recruited into the study from 8 hospitals during 2009-2011. 66.58\% were female, $28.01 \%$ aged $16-25$ years old, and main vehicle was motorcycle (78.85\%). $29.31 \%$ of subjects had been admitted at the hospital, $77.06 \%$ had a length of admission $\leq 31$ days, $2.39 \%$ diability found, $84.81 \%$ had medical cost $\geq 5000$ baht. Univariate analysis found alcohol used, types of vehicle, medical cost, and medical surgery were statistical different between sex.

In 7 police stationts, 2339 cases had been recruited into the analysis. $71.43 \%$ were females, $27.61 \%$ were aged $16-25$ years old, $60.96 \%$ were married, $92.02 \%$ were Buddhism. The main type of vehicle was the cars $(56.60 \%), 67.29 \%$ had their accident on the highways, and $60.66 \%$ had accidents on the day time (06.00 am.-06.00pm.), and those $13.12 \%$ drank alcohol. Conclusions Thailand needs the specific study for improving driving safety behaviours and also an effective regulation to control for traffic accident.

\section{CONTRIBUTION TO THE PREVENTION OF OCCUPATIONAL STRESS}

Kandouci Chahrazed, Belhadj Zoubida, Baraka Fatiha, Kandouci Baderdine Abdelkrim. University of Sidi Bel-Abbes, Sidi Bel-Abbes, Algeria

10.1136/oemed-2014-102362.183
Objectives The objectives of this study were to assess the importance of the mental suffering of employees in the service sector of a city in western Algeria and to identify risk factors and moderators of this suffering in order to develop a effective prevention.

Method Standardised questionnaires were subjected to 753 employees in the tertiary sector. These questionnaires include three categories: A social and professional record (21 items), Maslach Burn Out Inventory: MBI (22 items), Job Personal Interaction Scale: JPIS 35 questions on the perception of the work environment by the individual divided into 6rubriques (workload and unpredictability, control, rewards, recognition and fairness at work, social support, conflicts and perceived value valuri work and training)

The data collected were anonymous and confidential. Data analysis was performed using SPSS (version 17.0). Univariate analysis was performed (chi-square Pearson correlations and a multivariate analysis (logistic regression).

Results The state of burn-out was $23.6 \%$ after logistic regression the main social determinants of psychological distress in the overall sample one taking medication to relieve pain $(\mathrm{p}=$ 0.0002) remained significant.

Regarding the determinants "professional" contact with the public and strong mode part of work were significant respectively ( $p=0.0017$ and 0.0042$)$.

Moderators of stress for the multivariate analysis recognised two subscales of bad training $(p<0.01)$ and conflicts of values and perceived value $(\mathrm{p}=0.02)$.

Conclusions Preventive actions to reduce or eliminate risk factors directly affect the environment and source of work: training more relevant, better organisation of work, especially the riding tasks and recognition of work done.

\section{EVALUATION OF THE PREVALENCE OF URINARY INCONTINENCE SYMPTOMS IN ADOLESCENT FEMALE SOCCER PLAYERS AND THEIR IMPACT ON QUALITY OF LIFE}

${ }^{1}$ Antonio Fernandes, ${ }^{1}$ Fatima Fitz, ${ }^{2}$ Alexandre Silva, ${ }^{3,1}$ Eduardo Filoni, ${ }^{3}$ José M Filho. ${ }^{1}$ University of Mogi Das Cruze, Mogi Das Cruzes, São Paulo, Brazil; ${ }^{2}$ Cruzeiro Do Sul University, São Paulo, São Paulo, Brazil; ${ }^{3}$ State University of Campinas, Campinas, São Paulo, Brazil

\subsection{6/oemed-2014-102362.184}

Objectives To evaluate the prevalence, reliability and severity of symptoms of urinary incontinence (UI) in adolescent female soccer players and the impact of those symptoms on quality of life. Method The present work is a cross-sectional study of 59 female adolescents divided into a group of athletes, which included 35 adolescent amateur soccer players aged between 12 and 19 years $(15.6 \pm 2.0)$, and a control group, which included 24 adolescents aged 11 to 19 years $(14.8 \pm 2.4)$ who did not practice any sports. The International Consultation on Incontinence Questionnaire - Short Form (ICIQ-SF), the pad test and King's Health Questionnaire (KHQ) were used for evaluation.

Results The athletes displayed $62.8 \%$ positivity the pad test and the ICIQ-SF, whereas the control group exhibited $25 \%$ positivity. A medium agreement of 0.45 was found between the applied evaluation scales, as assessed with Cohen's kappa coefficient. In terms of quality of life (as assessed with the KHQ), the athletes exhibited a score of 35.2 in the General Health domain, 37.3 in the Emotions domain and 26.5 in the Sleep/Energy domain. 
Conclusions In the present study, a high prevalence of UI symptoms was found in soccer athletes, with moderate reliability between the pad test and the ICIQ-SF; mild UI was found in both groups. The athletes had the highest scores on the General Health, Emotions and Sleep/Energy domains, which are considered to have the highest impact on quality of life.

\section{LIFE QUALITY IN WORKERS WITH RELATED MUSCULOSKELETAL DISORDERS}

${ }^{1}$ Andressa Soares, ${ }^{1}$ Fernanda Caetano, ${ }^{1}$ Joyce Braga, ${ }^{2}$ Antonio Fernandes, ${ }^{1,2}$ Eduardo Filoni. ${ }^{1}$ Cruzeiro Do Sul University, São Paulo, São Paulo, Brazil; ${ }^{2}$ University of Mogi Das Cruzes, Mogi Das Cruzes, São Paulo, Brazil

\subsection{6/oemed-2014-102362.185}

Objectives Analyse the quality of life of workers of administrative department who carry out repetitive functions in a medical certification central.

Method This study was carried out in a transversal analytical approaching. The sample was constituted by 62 workers of the administrative sector of a medical certification central in the state of São Paulo. As an instrument of gathering the data the used questionnaires were: Anamnesis Questionnaire with personal and professional data, Nordic Questionnaire, Job stress scale, SF-36 Quality of Life Questionnaire. The characterisation of the sample was obtained through descriptive statistics, where test $t$ and correlation of Pearson test were applied.

Results a According to the results of the analysis of the Nordic questionnaire, 33, 87\% mentioned feeling pain in the wrists and hands. In the correlation made among the data of SF-36 and Nordic questionnaire, it was showed that they presented complaints about the Nordic, minor was the score in the variables of SF-36: limitation by physical aspects, pain, vitality, emotional aspects and mental health.

Conclusions It is concluded that the most affected segments were wrists and hands, with 33, 87\%, followed by anklebone and feet with $16,13 \%$.

\section{COMPARATIVE STUDY ABOUT QUALITY OF LIFE BETWEEN WOMEN PRACTICING DANCE AND SEDENTARY WOMEN}

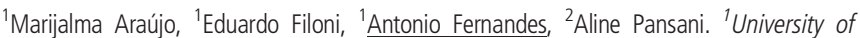
Mogi Das Cruzes, Mogi Das Cruzes, São Paulo, Brazili; ${ }^{2}$ Federal University of São Paulo, São Paulo, São Paulo, Brazil

\subsection{6/oemed-2014-102362.186}

Objectives This study aimed to compare Quality of life (QOL) of women who practice Jazz compared to sedentary women, in the Sports Centre-414 SESI in Sao Paulo - SP

Method We carried out a cross-sectional study, with women between 50 and 85 years old, divided into two groups: Activity Group (GA, n = 14) and Sedentary Group (GS, n = 14). QOL was analysed by the SF-36.

Results The GA had a significant improve in 6 domains of SF36 compared to GS $(\mathrm{p}<0.05)$.

Conclusions The results of this study suggest an improvement in the QOL of practitioners of jazz, especially in the physical and emotional aspects, compared to sedentary women.

\section{EFFECTS OF CHRONIC LOW-DOSE EXPOSURE TO IONISING RADIATION ON PHYSICIAN MICRO-VASCULAR STRUCTURE REVEALED BY NAIL FOLD CAPILLAROSCOPY}

${ }^{1}$ Pascal Wild, ${ }^{2}$ Christine Gauron, ${ }^{3}$ Christian Derock, ${ }^{3}$ Karine Champion, ${ }^{3}$ Pascal Cohen, ${ }^{4}$ Caroline Menez, ${ }^{5}$ Anne-Sophie Tellart, ${ }^{6}$ Hélène Thiel, ${ }^{1}$ Michel Grzebyk, ${ }^{7}$ Laurent Donadille, ${ }^{8}$ Raffaele Pennarola, ${ }^{9}$ Dominique Choudat. ${ }^{1}$ INRS, Vandoeuvre, France; ${ }^{2}$ INRS, Paris, France; ${ }^{3}$ APHP, Paris, France; ${ }^{4}$ University Hospital, Grenoble, France; ${ }^{5}$ University Hospital, Lille, France; ${ }^{6}$ University Hospital, Clermont-Ferrrand, France; ${ }^{7}$ IRSN, Fontenay Aux Roses, France; ${ }^{8}$ Naples University, Naples, Italy; ${ }^{9}$ University Paris Descartes, Paris, France

\subsection{6/oemed-2014-102362.187}

Objectives The aim of this study was to assess the long term pre-clinical effects of low-dose radiation on the micro-vascular structure among interventional physicians whose hands are exposed to ionising radiation in their daily practice.

Method The study, approved by the ethics committee, included 186 radiation-exposed (surgeons, cardiologists and radiologists) and 35 unexposed physicians. The study participants filled in a questionnaire describing their present and past daily practice from which the present and cumulative radiation exposures were estimated. Their dermal microcirculation was assessed by capillaroscopy of the nailfold of 8 fingers -thumbs excluded- of each study participant. Two quantitative scores characterising respectively extravasation and morphological abnormalities were obtained based on post-hoc codings of seven semi-quantitative indices by five capillaroscopists. These assessments were randomised and were blind to the exposure. The effect of the radiation exposure on both features was modelled using multilevel proportional odds regression adjusted for potential confounders. Results The exposure intensity of each act was greatest among surgeons but with a lesser number of acts. The mean estimated cumulated exposure was largest among radiologist and cardiologists.

No effect of the exposure could be detected on the extravasation score. The morphological anomaly score increased significantly with duration of exposure and cumulative exposure indices among surgeons and interventional radiologists contrary to cardiologists among which no effect could be detected.

Conclusions Capillaroscopy showed significant effects of chronic low-dose exposure to ionising radiation on micro-vascular structure among exposed physicians but its interest for individual monitoring has not been demonstrated.

\section{ASSESSMENT AND ESTIMATES OF EXPOSURE TO SYNTHETIC AMORPHOUS SILICA AT FIVE GERMAN PRODUCTION PLANTS}

${ }^{1,2}$ Peter Morfeld, ${ }^{3}$ Dirk Taeger, ${ }^{4}$ Heike Mitura, ${ }^{5}$ Axel Bosch, ${ }^{6}$ Adrian Nordone, ${ }^{7}$ Reinhard Vormberg, ${ }^{8}$ Robert McCunney, ${ }^{3}$ Rolf Merget. ${ }^{1}$ Institute for Occupational Epidemiology and Risk Assessment (IERA) of Evonik Industries, Essen, Germany; ${ }^{2}$ Institute and Policlinic for Occupational Medicine, Environmental Medicine and Prevention Research, Köln, Germany; ${ }^{3}$ Institute for Prevention and Occupational Medicine of the German Social Accident Insurance, Bochum, Germany; ${ }^{4}$ AQura GmbH, Hanau, Germany; ${ }^{5}$ Wacker Chemie AG, Burghausen, Germany; ${ }^{6}$ Cabot Corporation,

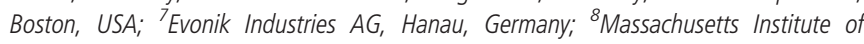
Technology (MIT), Boston, USA

10.1136/oemed-2014-102362.188

Objectives Synthetic amorphous silicas (SAS) are nanostructured polymorphs of silicon dioxide. We compared two different exposure assessments.

Method This study estimated cumulative exposure to inhalable SAS dust in 484 male workers from five German SAS producing plants. Two procedures (P1, P2) were applied. P1 was based on 